\title{
Hormonal alterations in PCOS and its influence on bone metabolism
}

\author{
Abhaya Krishnan and Sridhar Muthusami \\ Department of Biochemistry, Karpagam University, Coimbatore, Tamil Nadu, India
}

Correspondence should be addressed to S Muthusami Email

sridharuniv@gmail.com or sridhar.m@kahedu.edu.in

\begin{abstract}
According to the World Health Organization (WHO) polycystic ovary syndrome (PCOS) occurs in $4-8 \%$ of women worldwide. The prevalence of PCOS in Indian adolescents is $12.2 \%$ according to the Indian Council of Medical Research (ICMR). The National Institute of Health has documented that it affects approximately 5 million women of reproductive age in the United States. Hormonal imbalance is the characteristic of many women with polycystic ovarian syndrome (PCOS). The influence of various endocrine changes in PCOS women and their relevance to bone remains to be documented. Hormones, which include gonadotrophin-releasing hormone $(\mathrm{GnRH})$, insulin, the leutinizing/follicle-stimulating hormone (LH/FSH) ratio, androgens, estrogens, growth hormones $(\mathrm{GH})$, cortisol, parathyroid hormone (PTH) and calcitonin are disturbed in PCOS women. These hormones influence bone metabolism in human subjects directly as well as indirectly. The imbalance in these hormones results in increased prevalence of osteoporosis in PCOS women. Limited evidence suggests that the drugs taken during the treatment of PCOS increase the risk of bone fracture in PCOS patients through endocrine disruption. This review is aimed at the identification of the relationship between bone mineral density and hormonal changes in PCOS subjects and identifies potential areas to study bone-related disorders in PCOS women.
\end{abstract}

Key Words

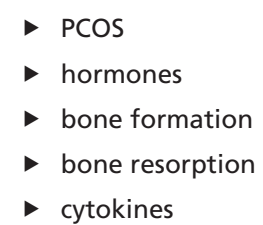

Journal of Endocrinology (2017) 232, R99-R113

\section{Introduction}

Polycystic ovary syndrome (PCOS) also called as hyperandrogenic anovulation or Stein-Leventhal syndrome is a multifactorial and polygenic condition. It is a common endocrine system disorder among women of reproductive age characterized by anovulation, hyperandrogenism and polycystic ovarian morphology. The diagnosis of PCOS is based on Rotterdam criteria with the presence of any of two of the following conditions: chronic anovulation, clinical/ biochemical parameters for hyperandrogenism or polycystic ovary on ultrasonography. The first reproductive feature of PCOS was discussed in the fifth century by Hippocrates. The observable sign of androgen excess coupled with metabolic abnormalities were reported in ninth century.
Later in 1844, Cherean gave the first description of enlarged smooth polycystic ovaries. The menstrual irregularity and infertility associated with PCOS were reported by Stein and Leventhal in 1935. They recommended ovarian wedge resectioning for its improvement. Hence, the name SteinLeventhal syndrome was proposed for enlarged ovaries associated with hirsutism, menstrual irregularity, infertility and obesity. The cause of PCOS is multifactorial and is not fully identified. It is due to a combination of genetic and environmental factors. A dysfunction of the hypothalamicpituitary-ovarian or adrenal axis was proposed to be the cause of hyperandrogenemia in women with PCOS (Hall et al. 1998, Baptiste et al. 2010). Risk factors for the 
onset of PCOS include obesity, lack of physical exercise, family history and diabetes mellitus. PCOS women have higher risk of developing insulin resistance, hypertension, psychiatric disorders, dyslipidemia, diabetes, cancer and osteoporosis.

This review is focused on documenting the available information delineating various hormonal factors and their relevance to alterations in bone mass of women suffering from PCOS. The hormonal factors include GnRH, LH/FSH ratio, estrogens, androgens, insulin, cortisol, growth hormone, vitamin D, PTH and calcitonin.

\section{Insulin}

The co-existence of diabetes mellitus with clinical signs of androgen excess in post-menopausal women was first reported in 1921, the so-called Achard-Thiers syndrome or diabetes of the bearded women. Insulin resistance is associated with a variety of reproductive abnormalities in women with PCOS. The circulating level of insulin in normal individuals is $6-15 \mu \mathrm{IU} / \mathrm{mL}$. In women with PCOS, the level goes up to $22 \mu \mathrm{IU} / \mathrm{mL}$ (Joshi et al. 2014). Hyperinsulinemia may play a vital role in the development of PCOS and is responsible for increased levels of androgens. The increased androgens in PCOS women can in turn cause insulin resistance and cause diabetes mellitus and associated diabetes.

The presence of functional insulin receptor (IR) is identified in the theca cells (Nestler et al. 1998) of ovary and osteoblast of bone (Wang \& Zhong 2013). Hyperinsulinemia is considered to be a causal factor for hyperandrogenemia as insulin can directly induce excess androgen production by theca cells (Dunaif 1997).

Various signaling mechanisms are implicated in the signal transduction of insulin. Binding of insulin to its receptor activates the translocation of steroid regulatory element-binding protein 1 (SREBP-1) from the cytoplasm to the nucleus through phosphoinositide 3 kinase (PI3K), phosphoinositide-dependent kinase 1 (PDK1) and protein kinase C (PKC) activation. SREBP-1 is a transcription factor responsible for the biosynthesis of various fatty acids (Shao \& Espenshade 2012). Insulin regulates SREBP activation and translocation from cytoplasm into the nucleus through PI3K/Akt and mammalian target of rapamycin (mTOR) signaling pathway (Baptiste et al. 2010).

Sex hormone-binding globulin (SHBG) levels are negatively correlated with the circulating levels of insulin or with the degree of insulin resistance in women with or without PCOD suggesting the suppressive effect of insulin on SHBG. Treatments aimed at improving insulin resistance reduced androgen levels (Baillargeon 2005).

\section{Effect of insulin at physiological levels on bone in women}

Physiological levels of insulin exert anabolic effect on bone. They reduce the ability of PTH to activate protein kinase $\mathrm{C}$ in osteoblasts and inhibit bone resorption (McCarty 1995). In addition, insulin is known to promote collagen production by osteoblasts (McCarty 1995). These findings imply that efficient insulin activity may exert an anabolic effect on bone. There is specific evidence that insulin may work to stimulate osteoblast differentiation, which in turn would enhance the production of osteocalcin, the osteoblast-produced peptide that can stimulate pancreatic $\beta$-cell proliferation and skeletal muscle insulin sensitivity (Klein 2014). However, an elevated level of insulin in PCOS women leads to insulin resistance resulting in the deterioration of BMD.

\section{Effect of insulin resistance on bone in PCOS women}

Insulin signaling attenuates bone formation by decreasing the expression of osteoprotegerin (OPG) (Clemens \& Karsenty 2011). This may in turn increase the bone resorption as osteoprotegerin is an inhibitor of receptor activator of nuclear factor kappa B ligand (RANKL). Wang and coworkers (Wang \& Zhong 2013) reported that insulin increases the expression of RANKL by MG63 osteoblast and influences osteoclastogenesis. These actions appear to mimic the action of PTH. Osteoprotegerin is synthesized in osteoblast and a substrate trapping assay documented that insulin receptor is a substrate of osteoblast protein tyrosine phosphatase (OST-PTP) in osteoblast. Insulin signaling in osteoblast decreases osteoprotegerin expression. The decrease in OPG/RANKL can result in an increased expression of Tcirg1 in osteoclast, which encodes for a proton pump and contributes to the acidification of the resorption lacunae. This acidic $\mathrm{pH}$ is sufficient to decarboxylate and activate the osteocalcin molecule. The undercarboxylated molecule on the other hand has been shown to facilitate/alter pancreatic $\beta$-cell proliferation, insulin expression, insulin secretion, insulin sensitivity and energy expenditure (Clemens \& Karsenty 2011). Thomas and coworkers (Thomas et al. 1998) studied the immunochemical evidence of insulin receptor expression by mature mono and multinucleated murine osteoclast-like cells generated in vitro and in primary neonatal and mouse osteoclasts. These data are consistent with an effect of insulin on bone resorption.

Published by Bioscientifica Ltd. 


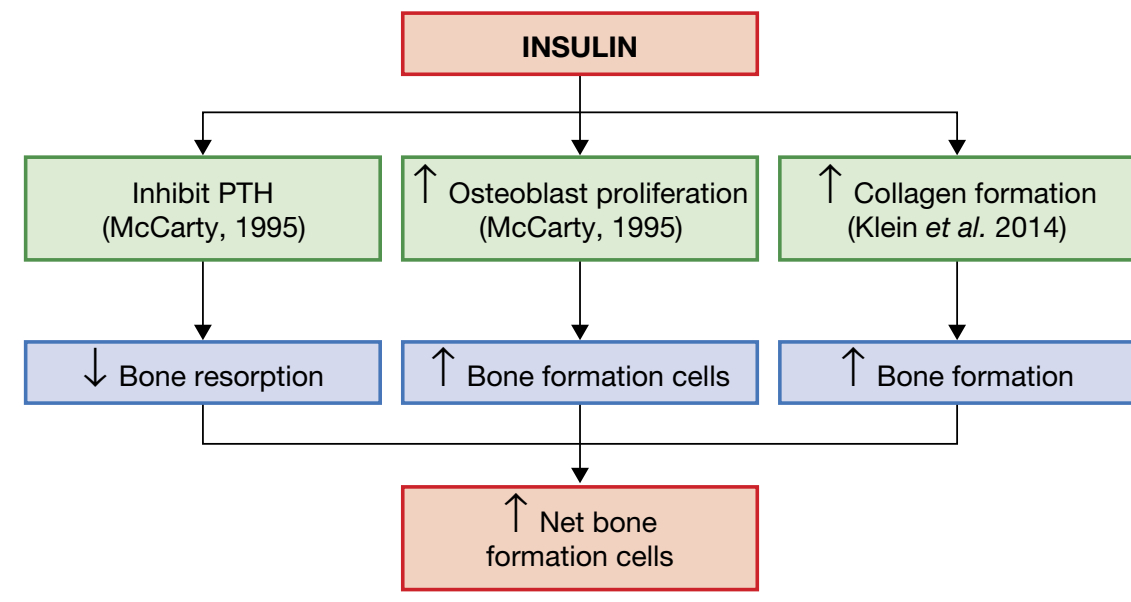

\section{Figure 1}

Schematic representation showing the effects of insulin on bone formation at physiological level. A full colour version of this figure is available at http://dx.doi.org/10.1530/JOE-16-0405.
Insulin affects bone remodeling by decreasing both bone formation and resorption (Huang et al. 2010). High level of insulin affects the recruitment and differentiation of osteoclast by impairing the RANKL signaling pathway. Huang and coworkers studied that the addition of insulin to the ex vivo osteoclast cell culture decreased the number of TRAP-positive cells (Huang et al. 2010). Therefore, it is possible that high level of insulin in women suffering from PCOD may bind to insulin receptor in osteoblast and reduce bone formation and can also affect bone resorption. Though some studies have identified the presence of insulin receptor on osteocalst, the exact mechanism by which insulin causes bone resorption through IR on osteoclast and whether the levels of bone resorption markers, tartrate-resistant acid phosphatase 5b (TRAP 5b) and cathepsin $\mathrm{K}$ are elevated in PCOS patients compared to normal remain to be documented.

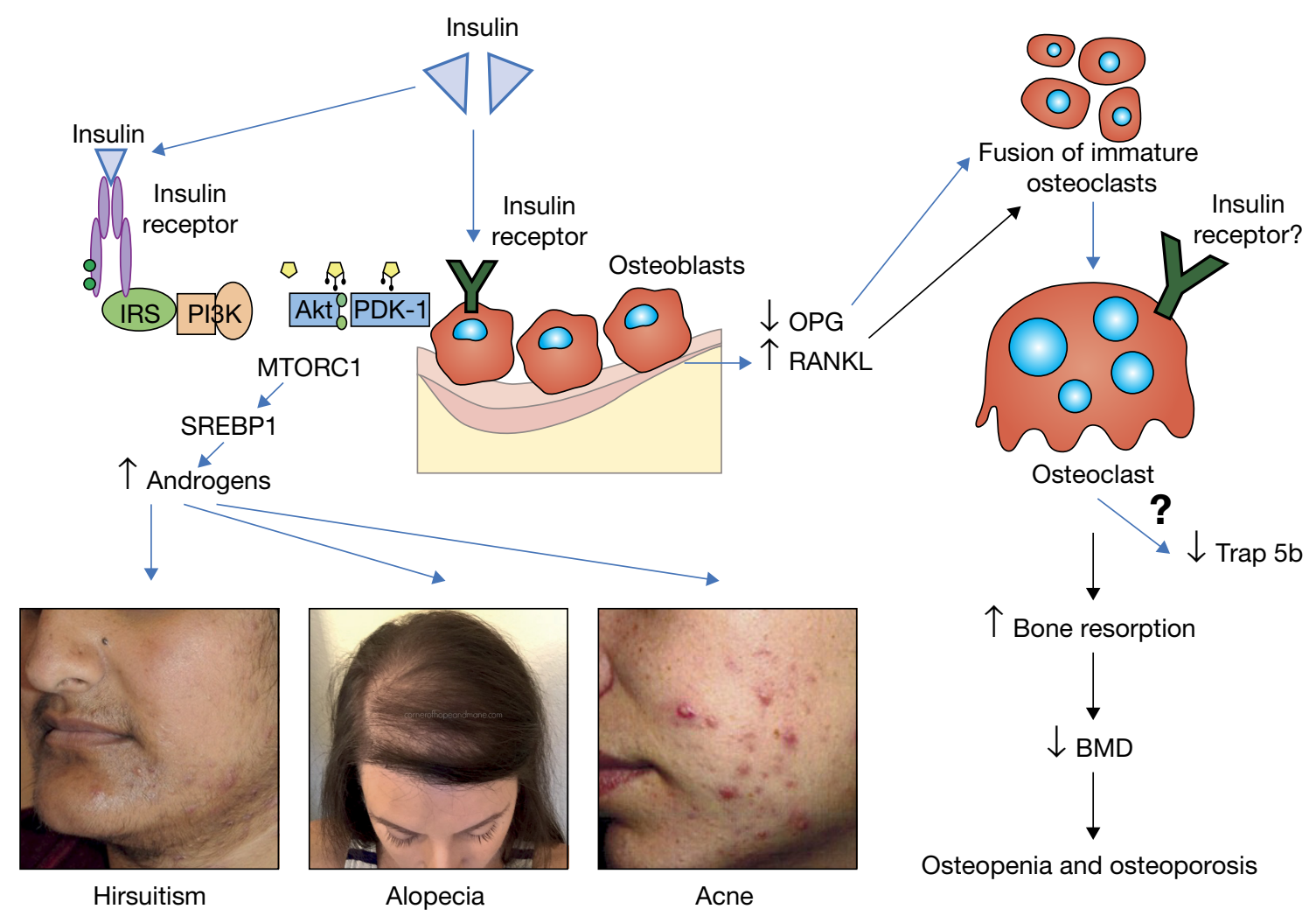

Figure 2

Schematic representation showing the possible effects of increased levels of circulating insulin levels and insulin resistance in women suffering from PCOS. A full colour version of this figure is available at http://dx.doi.org/10.1530/JOE-16-0405.

http://joe.endocrinology-journals.org DOI: $10.1530 / \mathrm{JOE}-16-0405$ (c) 2017 Society for Endocrinology Printed in Great Britain
Published by Bioscientifica Ltd 


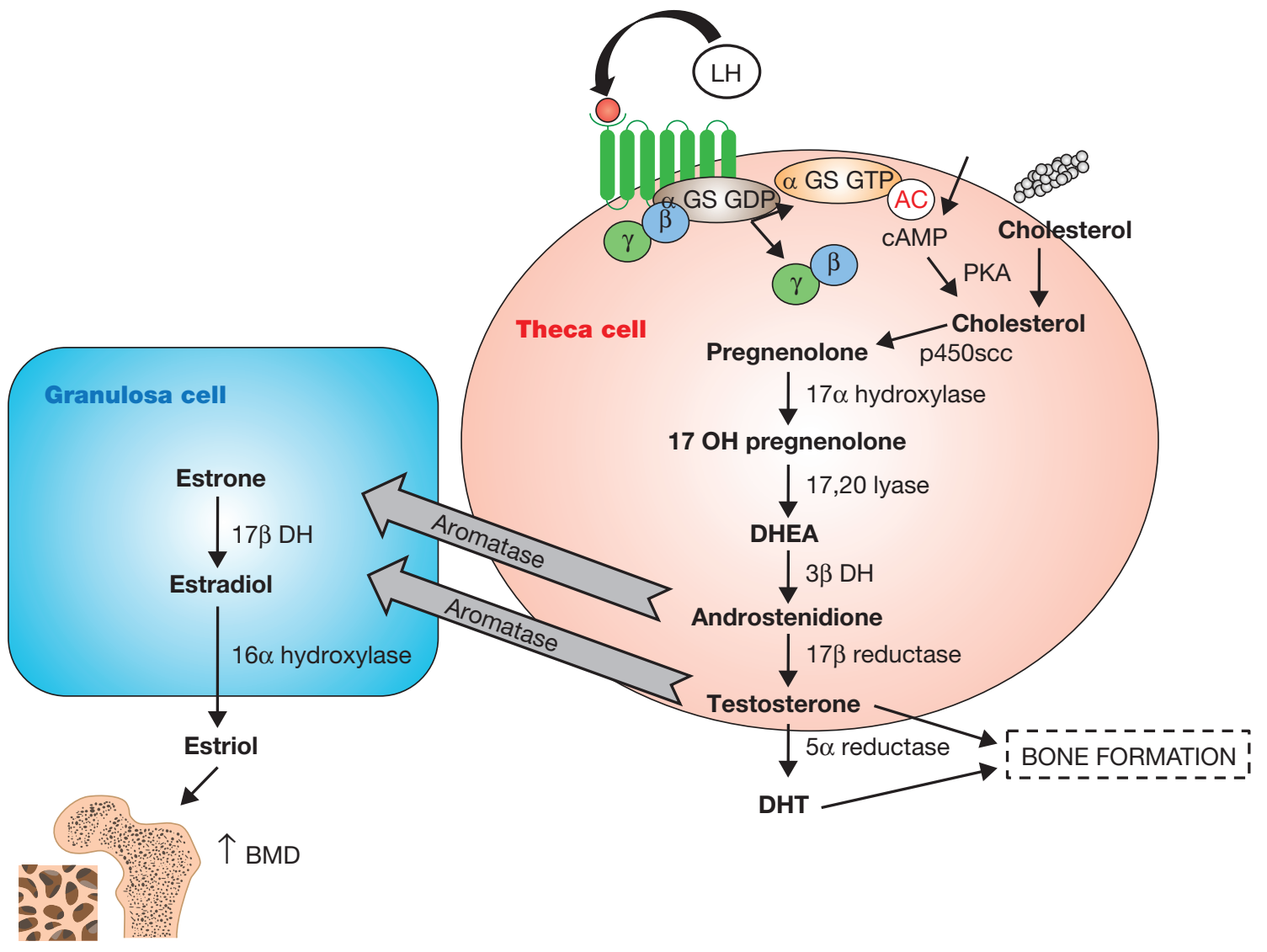

Figure 3

Schematic representation showing the effects of androgen/(s) on BMD. AC, adenylate cyclase; CAMP, cyclic adenosine mono phosphate; PKA, Protein kinase A; DHEA, dehydroepiandosterone. A full colour version of this figure is available at http://dx.doi.org/10.1530/JOE-16-0405.

The hypothetical picture depicting the role of insulin in osteoblast and osteoclast are shown in Fig. 1. The schematic representation of insulin resistance and its influence on bone metabolism is provided in Fig. 2 .

\section{Androgens}

Hyperandrogenism is defined by the state characterized or caused by the excess production of androgen or secretion of androgen, which is usually manifested by acne, hirsutism or frontal alopecia. As androgen excess is the main feature of PCOS, it is of great importance to clearly define how this androgen is produced. Androgens are part of the steroid family, mainly synthesized in ovary and adrenal gland. Cholesterol is the precursor for pregnenolone being then converted to steroid hormone after a series of enzymatic process. In the ovary, the first step of androgen production is performed in LH-stimulated theca cells, as these cells express the cytochrome P450c17 gene. It is the key enzyme for androgen biosynthesis hence referred as 'qualitative regulator of steroidogenesis' (Miller 2002). Thecal cells synthesize dehydroepiandrosterone (DHEA) and androstenedione. These precursors will then be converted to estrogen by granulosa cells, which express the enzyme P450 aromatase (Mendelson \& Kamat 2007). Ovaries also directly secrete androgen in circulation, mainly androstenedione and testosterone. Ovarian androgen do not regulate $\mathrm{LH}$ production through feedback mechanism; hence, in women as opposed to men, excess free testosterone or androstenedione will not reduce ovarian production of these androgens (Baptiste et al. 2010).

In PCOS, the ovaries produce upto $60 \%$ of androgens, whereas adrenal gland contributes the remaining 40\% (Cedars et al. 1992). It is established that androgens from both the adrenal gland and the ovary are the underlying source of hyperandrogenism in PCOS women.

Women with polycystic ovarian syndrome have abnormalities in the metabolism of estrogen and androgen (Zborowski et al. 2000, Baptiste et al. 2010). PCOS can 


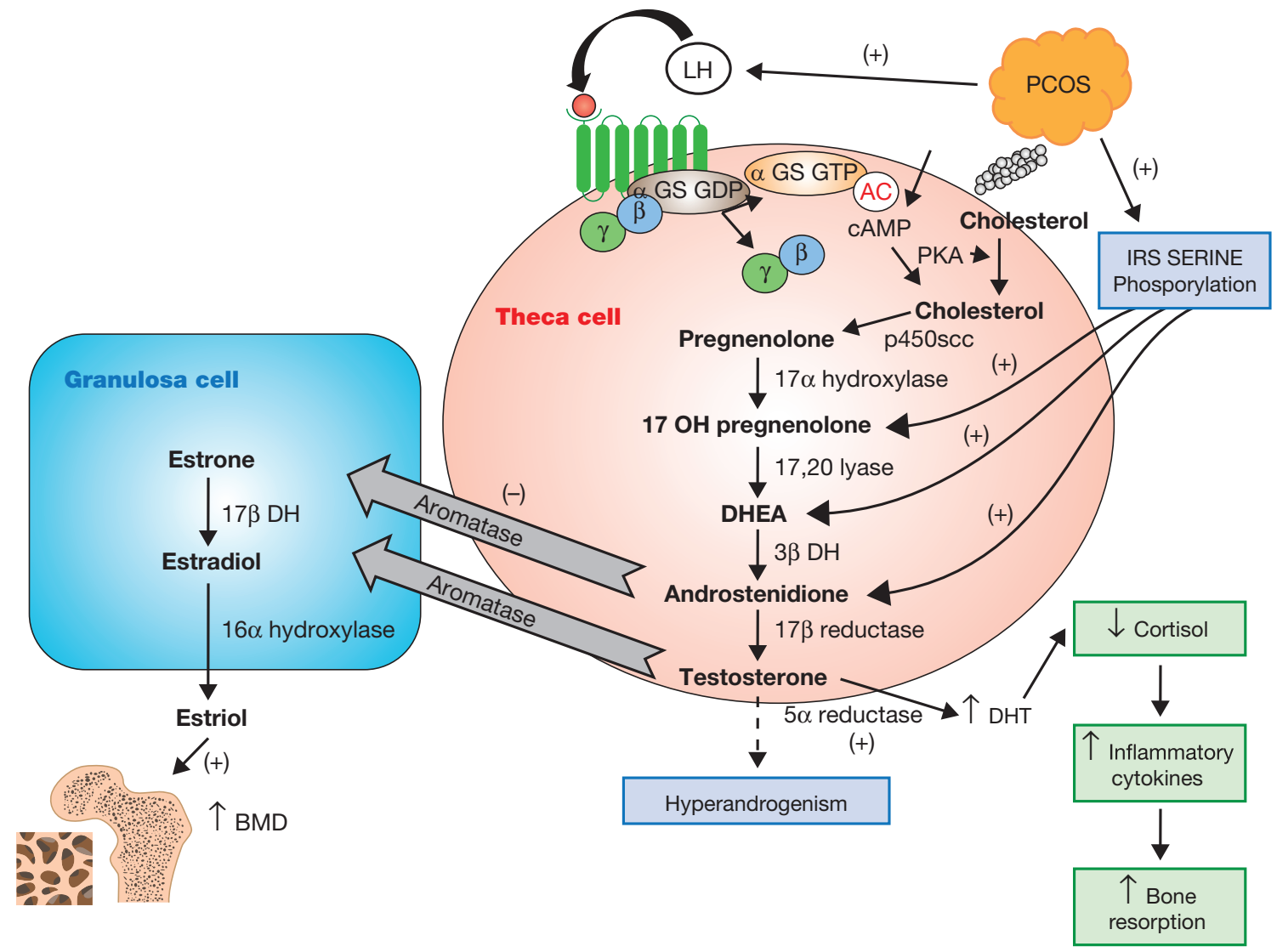

Figure 4

Schematic representation showing possible effects of elevated androgen/(s) level during PCOS on BMD. A full colour version of this figure is available at http://dx.doi.org/10.1530/JOE-16-0405.

result from abnormal function of the hypothalamicpituitary-ovarian axis (HPO axis).

In mammalian ovaries, LH induces androgen biosynthesis by theca interna cells. However, FSH stimulates aromatase activity by granulosa cells. Co-ordinated action of these two cells and pituitary hormones forms the basis of the two-cell, twogonadotropin hypothesis for biosynthesis of estrogen (Liu \& Hsueh 1986). LH and FSH secreted by the pituitary gland in the brain are the hormones that encourage ovulation. LH and FSH usually range between 5 and $20 \mathrm{IU} / \mathrm{mL}$ (Sterling 2015). Most women have equal amount of LH and FSH during the early part of their life. However, there is a LH surge in which the amount of LH increases to about $25-40 \mathrm{IU} / \mathrm{mL} 24 \mathrm{~h}$ before ovulation. Once the egg is released from the ovary, LH level goes back down, although women with PCOS still have LH and FSH between 5 and $20 \mathrm{IU} / \mathrm{mL}$. Their LH level is often two to three times that of FSH level. It is typical for women with PCOS to have an LH level of about $18 \mathrm{IU} / \mathrm{mL}$ and FSH of $6 \mathrm{IU} / \mathrm{mL}$. This situation is called an elevated LH-to-
FSH ratio (Sterling 2015). This change in LH-to-FSH ratio is enough to disrupt ovulation. It has been recently shown to elevate androgen production in PCOD women (Dumitrescu et al. 2015).

LH hypersecretion, both basally and in response to GnRH, is a characteristic hallmark of PCOS (Barnes et al. 1989). Thus, this LH hypersecretion is found to be the primary abnormality in classic PCOS causing androgen excess (Tsilchorozidou et al. 2004).

The LH/GnRH pulses are persistently rapid in PCOS subjects leading to hyperandrogenemia and impaired follicular maturation. This reflects the insensitivity of the hypothalamic GnRH pulse generation to estrogen/ progesterone inhibition. This insensitivity could be a potential mechanism for the perimenarchal abnormalities in hyperandrogenemic PCOS women (Tsilchorozidou et al. 2004).

The reduction in hypothalamic progesterone sensitivity appears to be mediated by elevated androgens because sensitivity can be restored with the androgen receptor blocker flutamide (Blank et al. 2006). It is hence 


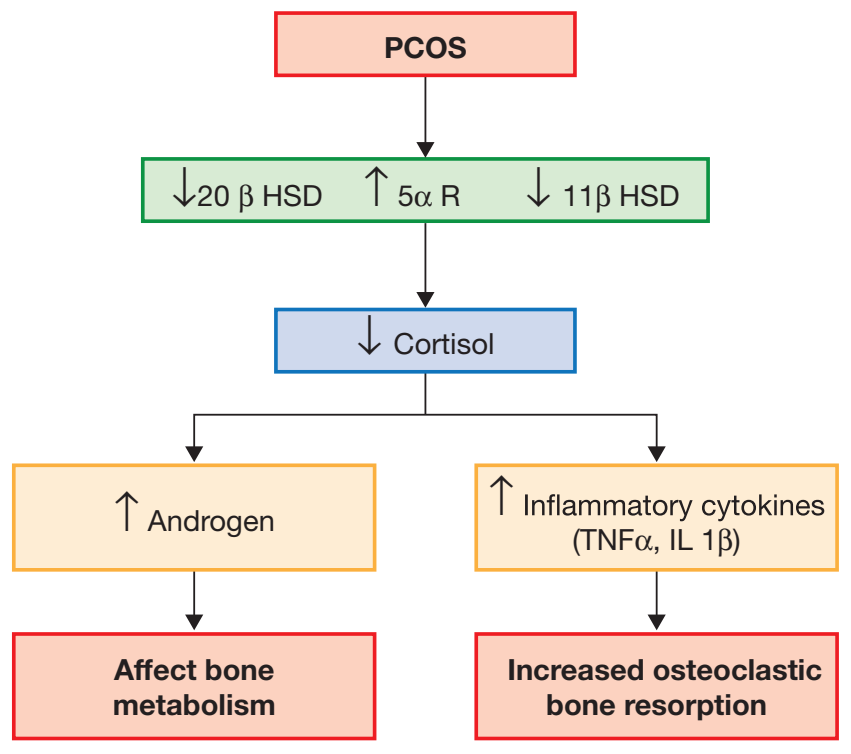

Figure 5

Schematic representation showing the possible effects of PCOS on cortisol level and BMD. $5 \alpha$ R, $5 \alpha$-reductase; $11 \beta$-HSD, $11 \beta$ hydroxysteroid dehydrogenase; 20及-, $20 \beta$ hydroxysteroid dehydrogenase. A full colour version of this figure is available at http://dx.doi.org/10.1530/JOE-16-0405.

proposed that peripubertal hyperandrogenemia may lead to persistently rapid GnRH pulse frequency via impaired hypothalamic feedback inhibition.

The gonadotropin level is also controlled by the ovarian steroid feedback on the anterior pituitary cells. There may be an abnormality of the serum sex steroid concentration leading to a stimulatory effect on $\mathrm{LH}$ secretion in PCOS.

A number of authors have proposed an alternative model of PCOS as a form of gonadotropin-dependent ovarian hyperandrogenism in which the central abnormality is an elevated intra-ovarian androgen concentration. It is reported that PCOS women have increased $17 \alpha$-hydroxy progesterone and androstenedione in response to LHbecause of abnormal enzymatic regulation of steroidogenesis. $\mathrm{LH}$ response to theca cells in PCOS women ovary is found to be much higher than that of normal women ovary. This dysregulation mainly involves the enzyme P450c17, which performs both 17-hydroxylation and 17,20-lyase function in both ovary and adrenal steroidogenic tissue.

In PCOS women, the activities of the enzyme P450c17 and 3 $\beta$-hydroxysteroid dehydrogenase (3 $\beta$-HSD) were increased more than 500\% and 1000\%, respectively (Nelson et al. 1999), whereas $17 \beta$-HSD activity remains unaffected. $\mathrm{C}_{17,20}$-lyase and $17 \alpha$-hydroxylase activities were also found to be elevated in PCOS women. Finally it is concluded that enhanced production of testosterone precursor may be the primary driving factor in the enhanced testosterone secretion in PCOS.

\section{Effect of androgen at physiological levels on bone in women}

Estrogen has been shown to increase bone mass in men and women (Bilezikian et al. 1998). Similarly, androgen receptors are expressed on the surface of all the three bone cells, osteoblast, osteoclast and osteocyte (Abu et al. 1997) in both men and women indicating the direct influence of androgen on bone. Shimodaira and coworkers (Shimodaira et al. 1996), demonstrated that osteoblasts of the MG-63 (male osteosarcoma cells) and HOS (female osteosarcoma) cell lines possess both 5a-reductase and aromatase activities. Dihydrotestosterone (DHT) is a potent non-aromatizable androgen. 5a-reductase will convert testosterone to DHT. DHT helps in the proliferation and differentiation of osteoblast cells (Lin et al. 2007). But whether level of 5a-reductase is elevated in the osteoblast cell of PCOS subjects is not yet studied.

Other than through sex steroid receptors, androgen influences bone metabolism through various other pathways including inhibition of bone resorption, by decreasing interleukin-6 (IL-6) and prostaglandin E (PGE) production, inhibiting the effect of PTH, by increasing calcium reabsorption from the intestine and preventing its excretion and by increasing vitamin $\mathrm{D}_{3}$ production. It

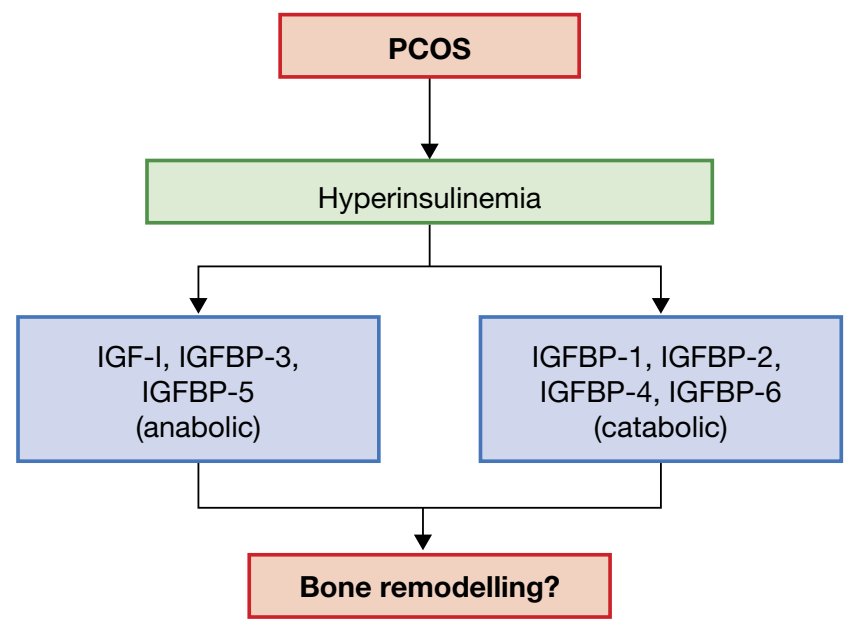

Figure 6

Possible mechanisms involving hyperinsulinemia, IGFBP-1 and IGF-1 in PCOS. These data show that the GH deficiency seen in PCOS patients can directly affect bone remodeling and can decrease BMD. A detailed study regarding which of the six IGFBPs is getting altered in PCOS subjects will help to understand whether there is catabolic or anabolic change occurring in bone during PCOS in relation to IGFBP level. A full colour version of this figure is available at http://dx.doi.org/10.1530/JOE-16-0405.

Published by Bioscientifica Ltd. 


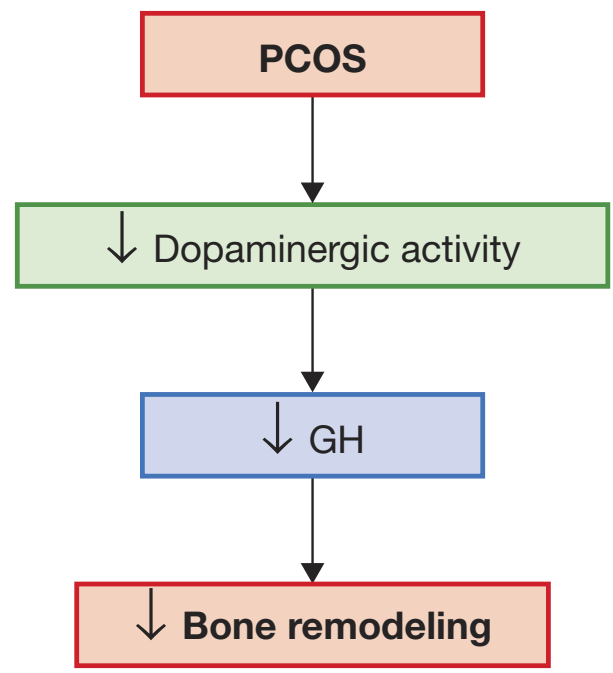

Figure 7

Schematic representation showing the possible effects of PCOS on growth hormone level (GH) and BMD. A full colour version of this figure is available at $h t t p: / / d x . d o i . o r g / 10.1530 / J O E-16-0405$.

also modulates the production of bone-related mitogenic growth factor and stimulates the transforming growth factor beta (TGF $\beta$ ) and insulin-like growth factor1 (IGF-1) gene expression (Hofbauer \& Khosla 1999). It amplifies IGF-2 receptor and their affinity for IGF-2 in human bone cells (Kasperk et al. 1989). Androgen exposure enhances osteoblast differentiation and the synthesis of extracellular matrix protein such as type 1 collagen, osteocalcin and osteonectin. Androgen also stimulates mineralization. Thus, androgen has got an important role in regulating bone matrix production and mineralization. A schematic representation of the influence of androgens and estrogens on bone is shown in Fig. 3.

Specific androgens may exert influences differentially across the various bone sites (Zborowski et al. 2000). Free testosterone is significantly associated with BMD at all the major skeletal sites including femoral neck lumbar spine and greater trochanter. Dehydroepiandrosterone sulfate (DHEAS) is correlated mainly with the BMD at femoral neck and radius. DHEAS has little androgenic activity and direct stimulatory effects on bone, and therefore, it may serve rather as a surrogate marker for the effects of DHEA, which can directly stimulate osteoblast proliferation and differentiation (Sawalha \& Kovats 2008). DHEA is found to increase BMD especially the spinal bone density in women. DHT has potent androgenic effect and is found to have a strong positive correlation with the BMD at total skeleton, lumbar spine and femoral region. Collectively, these studies suggest the possible anabolic effects of androgens on bone metabolism.

\section{Effect of androgen excess on bone in PCOS women}

The conversion of androgens to estrogens in the ovary and in extraglandular tissue, with subsequent binding at the estrogen receptor in target organs, is recognized as a primary mechanism of androgen action on bone metabolism. Adipocytes and stromal cells in fat tissue express $\mathrm{P} 450$ aromatase and are capable of converting adrenal and ovarian testosterone and androstenedione to $17 \beta$-estradiol and estrone, respectively. Obesity and fat mass have, in fact, been convincingly linked to increased bone mineral density (BMD) in older women. Similarly, osteoblast-like cells in bone in both men and women are able to aromatize androgens to estrogen. Moreover, aromatase deficiency and estrogen receptor polymorphisms in men have been shown to lead to osteopenia and sustained linear growth, with failure of epiphyseal closure. Estrogen replacement in aromatasedeficient males has also been shown to increase bone mass. These observations suggest that estrogen plays a crucial role in mediating bone mass in both men and women (Zborowski et al. 2000). Zborowski and coworkers (Zborowski et al. 2000) reported that BMD is higher in PCOS amenorrheic patients than non-PCOS amenorrheic patients, and also hyperandrogenic women with regular menses had significantly higher BMD than either amenorrheic hyperandrogenic women or controls. This hyperandrogenemia helps to preserve bone mass in PCOS women. But androgen has positive effect on bone

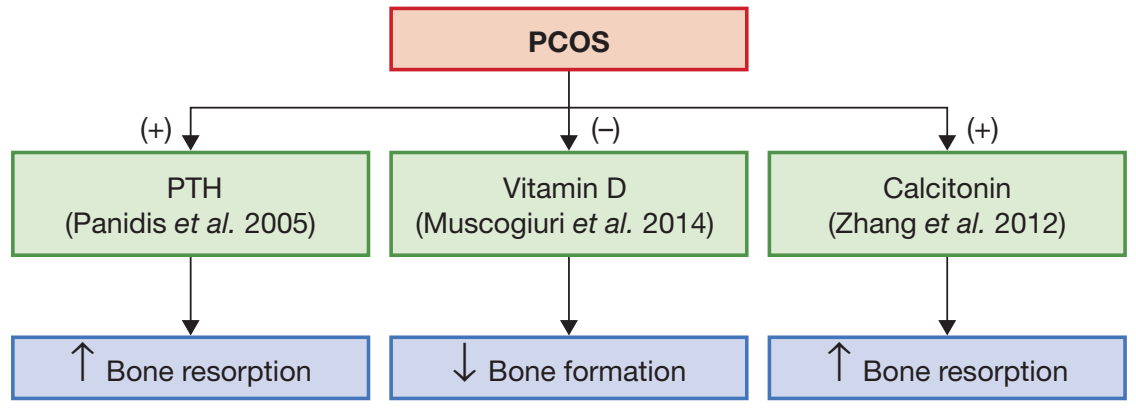

Figure 8

Schematic representation of the effect of PCOS on bone in relation to vitamin D, PTH and calcitonin. A full colour version of this figure is available at http://dx.doi.org/10.1530/JOE-16-0405.
๑) 2017 Society for Endocrinology Printed in Great Britain 


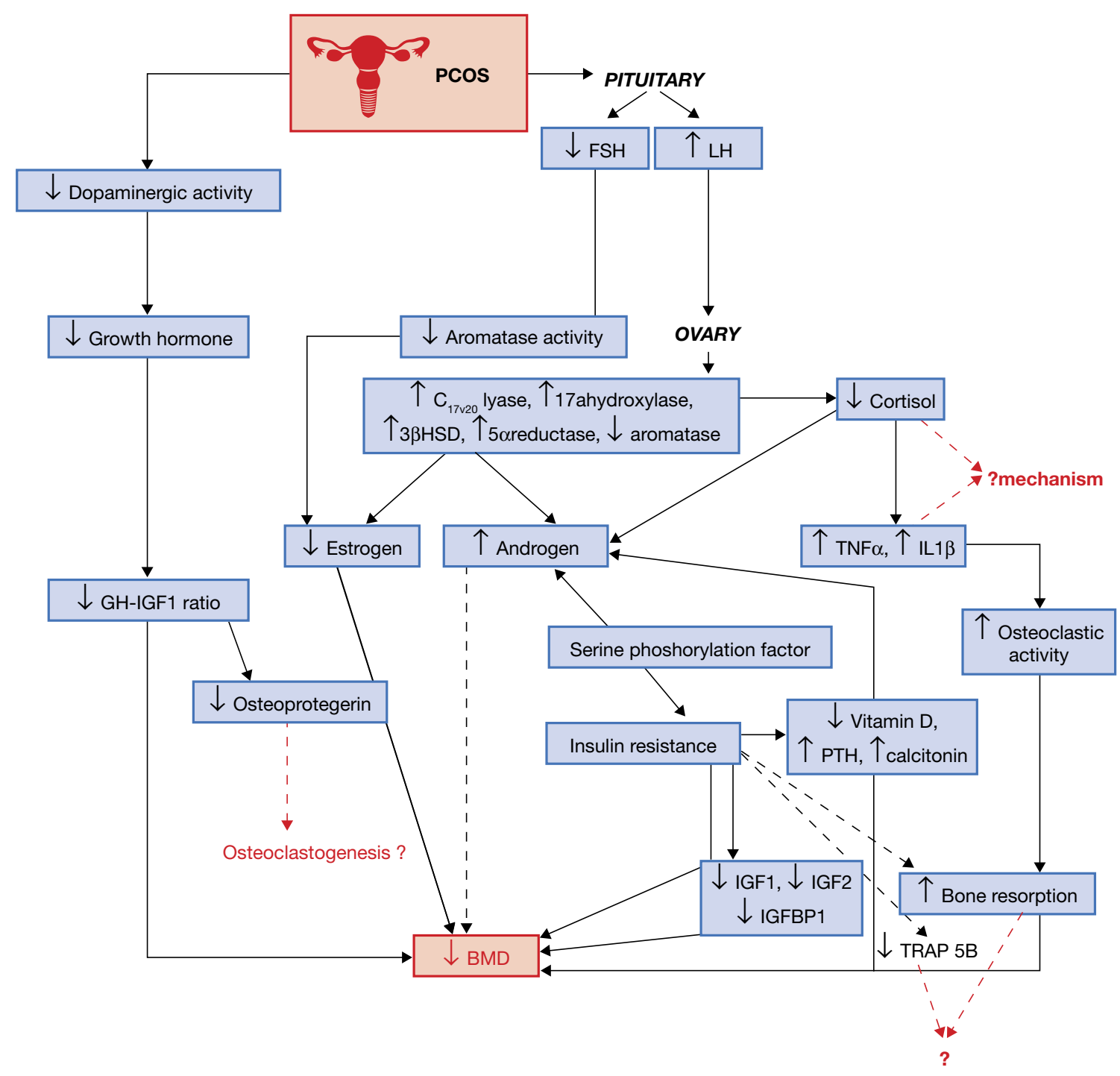

\section{Figure 9}

Schematic representation of various hormonal alterations in PCOS and its possible relation to the reduced BMD. A full colour version of this figure is available at http://dx.doi.org/10.1530/JOE-16-0405.

only in the presence of estrogen. Without the estradiol peak or progesterone production associated with normal menstrual cycle, there is no net positive effect for androgen on bone (Fig. 4, schematic representation showing the influence of androgens and estrogens on bone in female PCOS subjects). All these findings suggest that both estradiol and androgen have a critical role in maintaining bone mass. Studies have shown that androgen receptors are upregulated by androgen in bone and also by exposure to glucocorticoids, estrogen and 1,25-dihydroxyvitamin $\mathrm{D}_{3}$ (Notelovitz 2002) all of which are found to be reduced in PCOS condition, thus adversely effecting the regulation of BMD by androgens.
GnRH agonist has been recently proposed for the treatment of hirsutism in PCOD women. The treatment of GnRH agonist alone or in combination with antiandrogenic drug flutamide is found to reduce BMD in PCOS women. In contrast, GnRH treatment along with spironolactone (antiandrogenic drug) did not show any decrease in BMD (Moghetti et al. 1999). Spironolactone acts by inhibiting the binding of $\left[{ }^{3} \mathrm{H}\right]$ 5-alpha-dihydrotestosterone $\left(\left[{ }^{3} \mathrm{H}\right]\right.$ DHT) to the cytosolic and nuclear receptors. However, the mechanism of bone sparing effect of spironolactone remains unclear.

The LH stimulation of androgen synthesis appears to be augmented by factors such as inhibin and downregulated

Published by Bioscientifica Ltd 
Table 1 Hormonal alteration in PCOS.

$\begin{array}{lll}\frac{1}{1} \text { S. No. } & & \text { Hormonal alteration } \\ 2 & \text { Androgen elevation } \\ 3 & \text { Estrogen reduction } \\ 4 & \text { Increased insulin level/ resistance } \\ 5 & \text { Vitamin D reduction } \\ 6 & \text { PTH elevation } \\ 7 & \text { Growth hormone reduction } \\ 8 & \text { Cortisol reduction }\end{array}$

\section{Impact of bone}

Androgen elevation in PCOS is associated with reduced cortisol, which could probably result in increased IL1 $\beta$ and TNF $\alpha$ and impair bone formation

Estrogen is mainly required for the maintenance of bone in women. Hence a reduction in estrogen could largely impair bone formation and increase resorption through several mechanisms

Elevated LH/FSH ratio in PCOS women will lead to elevated androgen levels, which could probably result in impaired bone formation

Insulin resistance reported in PCOS is found to increase bone resorption by decreasing osteoprotegrin and increasing RANKL expression and thus impair bone formation Vitamin $D$ is an important calciotrophic hormone required for the maintenance of bone. Hence, a reduction in vitamin $D$ can impair bone remodeling

PTH is required for bone resorption. Elevated PTH can cause increased bone resorption in PCOS women

GH through IGF-1 directly stimulates osteoblast cell for bone formation and osteoclast for differentiation. Hence, decreased GH can result in decreased bone remodeling Cortisol reduction could probably result in increased IL-1 $\beta$ and TNF $\alpha$ and thus impair bone formation by factors such as activin, epidermal growth factor (EGF), TGF $\alpha$ and TGF $\beta$. Inhibin also inhibits FSH secretion. It was suggested that inhibin B from multiple small viable follicles should also cause increased LH and decreased FSH secretion (Chada et al. 2003).

It is noted that there is an increase in IGF activity in ovarian follicle of PCOS women. It increases androgen production by increasing P450scc enzyme activity and synergizing LH to upregulate P450c17 production (Sawetawan et al. 1996). The insulin androgen connection in PCOS appears to be amplified by several different mechanisms, notably in both the directions (Holte 1996). Testosterone may indirectly contribute to insulin resistance by facilitating free fatty acid release from abdominal fat, which again affects BMD.

The concentration of 5 - $\alpha$-androstane-3,17-dione (5 $\alpha$-reduced androgen) was found to be elevated in serum and follicular fluid of PCOS women compared with regularly cycling women indicating that there might be increased $5 \alpha$-reductase activity in polycystic ovaries. These reduced androgens are able to inhibit human granulosa aromatase by functioning as a competitive inhibitor of androgen substrate. It is unclear how increased activity of $5 \alpha$-reductase would impact bone metabolism on PCOS women, but there are several alterations in the endocrine milieu in women with PCOS that might play a role. Some studies have shown that $\mathrm{LH}$ and insulin-like growth factor-1 (IGF-1) stimulate and FSH inhibits 5a-reductase activity. Elevated serum LH concentrations are observed in some women with PCOS, and the follicular fluid concentration of IGF-1 is higher in PCOS than that in normal follicles. The potential exists that elevated $\mathrm{LH}$ and/or IGF-1 could stimulate $5 \alpha$-reductase activity in
PCOS (Jakimiuk et al. 1999). Similarly, there exists an inverse relationship between $5 \alpha$-reductase and aromatase activity. Thus, the $5 \alpha$-reduced androgen produced in PCOS women can lead to hyperandrogenism with decreased aromatase activity causing reduced estrogen synthesis, which can adversely affect the BMD of PCOS women.

Thus, the excess androgen present in PCOS subjects directly as well as through the involvement of various other factors like cytokines, insulin, etc. is affecting the bone mass. However, more research is still needed to unravel the exact mechanism by which androgen affects the BMD of PCOS subjects. Care should be taken while treating the subjects with anti-androgenic drugs. The exact mechanism by which an anti-androgenic drug is affecting the BMD is also not fully identified. Identifying the exact mechanism leads to formulate an effective strategy to treat bone-related disorders in PCOS women.

\section{PCOS and cortisol}

Alteration in cortisol metabolism can cause hyperandrogenism. It is found that in PCOS patients, there is an elevated activity of $5 \alpha$-reductase causing increased inactivation of cortisol or impaired 11 $\beta$-HSD and thus impaired regeneration of cortisol (Stewart et al. 1990, Rodin et al. 1994). The changes in the activity of these enzymes, that is $5 \alpha$-reductase, $11 \beta$-HSD and also $20 \beta$-HSD, support the concept of widespread dysregulation of steroid metabolism in PCOS (Tsilchorozidou et al. 2004). But this dysregulation does not seem to be the primary cause of

Published by Bioscientifica Ltd. 
PCOS because no correlation was found between serum androgen levels or urinary excretion of androgens with measurements of either $5 \alpha$-reductase or $11 \beta$-HSD activities (Tsilchorozidou et al. 2003, 2004). Impaired activity of these enzymes causes increased adrenocorticotropic hormone (ACTH) secretion with decreased negative feedback signaling thereby maintaining normal serum cortisol with increased adrenal androgen. Thus, adrenal androgen excess in PCOS is associated with increased inactivation of cortisol by $5 \beta$ - reductase that may lower cortisol blood levels and stimulate ACTH-dependent steroidogenesis (Gambineri et al. 2009). However, the level of inflammatory cytokines, tumor necrosis factor alpha (TNF $\alpha$ ) and interleukin 1 beta (IL1 $\beta$ ), which is having an inverse relation with cortisol is found to be elevated in PCOS patients (Coutinho \& Chapman 2011). These proinflammatory cytokines are found to be involved in chronic inflammatory bone disease characterized by bone loss around affected joints caused by increased osteoclastic bone resorption (Boyce et al. 2005). A schematic representation showing the effect of cortisol on bone in PCOS women is shown in Fig. 5. These cytokines may induce the resorption indirectly by affecting the production of the essential osteoclast differentiation factor, RANKL, and/or its soluble decoy receptor, OPG, by osteoblast/stromal cells or directly by enhancing the proliferation and/or activity of cells in the osteoclast lineage. Thus, decrease in anti-inflammatory hormone, cortisol, with a corresponding increase in inflammatory cytokines TNF $\alpha$ and IL1 $\beta$ seen in PCOS women can cause severe bone loss. The imbalance in the level of cortisol may thus impair BMD through $5 \alpha$-reducatse,

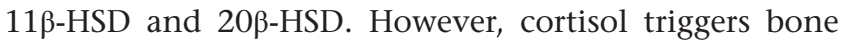
mineral resorption (removal) to free amino acids for use as an energy source through gluconeogenesis. Cortisol indirectly acts on bone by blocking calcium absorption, which decreases bone cell growth. The disruption to serum calcium homeostasis increases bone resorption and ultimately reduces BMD. Even a short bout of elevated cortisol secretion may cause a decrease in BMD. Excessive elevation of cortisol levels, such as in hypercortisolism or Cushing's syndrome, is linked to a high prevalence of osteoporosis and may be associated with the age-related decrease in BMD in the elderly (Mathis et al. 2013). But in the case of PCOS, cortisol is getting reduced and there is also a corresponding increase in androgen. Currently, there is no study regarding the effect of cortisol on bone in PCOS subjects.

\section{PCOS and growth hormone}

Growth hormone also has an effect on increased androgen production in women with PCOS (Morales et al. 1996). The secretion of growth hormone is regulated through a complex neuroendocrine system. The hypophysiotropic hormones GnRH and somatostatin exert regulatory and inhibitory influence on GH secretion, respectively. Both are further affected by some neurotransmitters like dopamine and opioids (Muller et al. 1999). In PCOS, the dopaminergic activity is found to be reduced (Paradisi et al. 1988) and thus can affect the GH level (Wu et al. 2000). The GH exerts most of its function through peripheral IGF-1 (Adashi et al. 1985, Katz et al. 1993), which in turn participates in the negative feedback regulation of GH (Katz et al. 1993, Muller et al. 1999). The hyperinsulinemia seen in PCOS can increase free IGF-1 production which in turn can decrease GH release through increased hypothalamic somatostatin secretion (Wu et al. 2000). Somatostatin release can also be directly stimulated by hyperandrogenemia as testosterone can increase somatostatin secretion.

Bone remodeling is severely affected by decrease in GH. This can cause gonadal loss of BMD (Olney 2003). $\mathrm{GH}$ can also exert direct effect on chondrocytes, which are involved in the bone growth at epiphyseal plates (Olney 2003). In vivo studies have demonstrated an important effect for growth hormone (GH) in the regulation of both bone formation and bone resorption. Thus, GH deficiency severely limits bone remodeling. GH directly and through IGF-1 stimulates osteoblast cells for bone formation and also osteoclast differentiation, thus helps in bone remodeling. It is now known that the majority of IGFs exist as complexes, bound to the six known fully characterized IGF-binding proteins (IGFBPs) and that IGFBPs modulate IGF actions both in a positive and negative manner (Thorén et al. 1998). IGFBPs have got both anabolic as well as catabolic effects on bone metabolism. Diminished levels of free and total IGF-1, IGFBP-3 and IGFBP-5, as well as the increased levels of IGFBP-1, IGFBP-2, IGFBP-4 and IGFBP-6, may contribute to diminished bone formation in osteoporotic patients (Jehle et al. 2010), indicating free and total IGF-1, IGFBP-3 and IGFBP-5 have anabolic, whereas IGFBP-1, IGFBP -2, IGFBP-4 and IGFBP-6 have catabolic role in bone metabolism (Jehle et al. 2010).

Studies have shown that in PCOS patients, the serum level of IGFBP-1 is significantly reduced (Wang \& Wang 2003). Hyperinsulinemia associated with PCOS is the 
important reason for this reduction. Reduced IGFBP-1 decreases the level of bound IGF-1 with increased free IGF-1 fraction, which will lead to hyperandrogenism in PCOS (Wang \& Wang 2003). A schematic representation showing the influence of hyperinsulinemia, insulin like growth factor and bone is given in Fig. 6 . The influence of PCOS on growth hormone and bone remodeling are shown in Fig. 7.

\section{Vitamin D, parathyroid hormone, calcitonin and PCOS}

PCOS women demonstrate an increased prevalence of obesity, hyperinsulinemia and insulin resistance (Balen et al. 1995, Ehrmann 2005), which are associated with alteration in the calciotrophic hormones PTH and 25-hydroxyvitamin D (25(OH)D). The main physiological role of vitamin $\mathrm{D}$ is the regulation of calcium and phosphorus homeostasis and to promote bone health. Several recent studies suggest that vitamin $\mathrm{D}$ is also involved in some non-skeletal actions that may lead to the pathogenesis of several endocrine diseases including PCOS (Muscogiuri et al. 2014). In PCOS patients, an inverse relationship between the vitamin D status and metabolic and hormonal disturbance has been reported in PCOS (Muscogiuri et al. 2014). Vitamin D influences glucose homeostasis and insulin sensitivity. Circulating level of $25(\mathrm{OH}) \mathrm{D}$ is inversely associated with insulin resistance (Alvarez \& Ashraf 2010). Vitamin D deficiency is common in women with PCOS, with $67-85 \%$ of women with PCOS having serum concentration of $25(\mathrm{OH}) \mathrm{D}<20 \mathrm{ng} / \mathrm{mL}$ (Thomson et al. 2012). It is found that decreased $25(\mathrm{OH}) \mathrm{D}$ level was associated with the salient features of PCOS including insulin resistance, ovulatory and menstrual irregulation, decreased pregnancy rate, hirsutism, hyperandrogenism, obesity and elevated cardiovascular disease (Thomson et al. 2012). Limited evidence shows that vitamin D supplementation shows a beneficial effect on menstrual cycle and insulin resistance in PCOS women. The vitamin D level and calcium metabolism in the body is mediated by vitamin D receptor (VDR). VDR gene polymorphism may be the associated reason for the endocrine dysfunction and insulin resistance in PCOS women (Dasgupta et al. 2015). Fig. 8 shows a schematic representation on the effects of PTH, Vitamin D, Calcitonin and their influence on bone metabolism in PCOS subjects.
Parathyroid hormone (PTH) and calcitonin are two peptides that play an important role in the calcium homeostasis through their action on osteoblast and osteoclast, respectively (Carter \& Schipani 2006). PCOS women had significantly higher PTH concentration than ovulatory women without hyperandrogenemia (Panidis et al. 2005). PCOS women are at increased risk of developing insulin resistance. Insulin resistance in turn has been associated with decreased concentrations of vitamin D metabolites and increased PTH concentrations (Kumar et al. 1994, Wareham et al. 1997). Panidis and coworkers (Panidis et al. 2005) reported that serum testosterone level is elevated with increased PTH independent of age, BMI and vitamin D concentration and can be related to the associated hyperandrogenemia seen in PCOS women.

In PCOS patients, the level of plasma calcitonin gene-related peptides (CGRP) is found to be elevated (Zhang et al. 2012). CGRP is a member of calcitonin family of peptides. It is a neuropeptide abundantly concentrated in the sensory nerve endings innervating bone metaphysis and periosteum. CGRP has shown to inhibit bone resorption in vitro and induce hypocalcemia in vivo (Valentijn et al. 1997). CGRP level is found to be positively correlated with the hormonal and metabolic parameters like insulin resistance, LH/FSH ratio and testosterone level, which are all the salient features of PCOS and thus may be involved in the pathophysiology of PCOS (Zhang et al. 2012). CGRP receptor is expressed on the surface of human granulosa cells and the administration of exogenous CGRP is found to elevate the level of testosterone. Testosterone cannot be synthesized directly by the granulosa cells because of the deficiency of $17 \alpha$-hydroxylase, but can be achieved by some stimulation (Goren et al. 1990). CGRP triggers the release of testosterone from theca cells, which may then be accumulated in the granulosa cells (Zhang et al. 2012). There also exists a positive feedback between CGRP and estradiol $\left(\mathrm{E}_{2}\right)$. Elevated $\mathrm{E}_{2}$ with its negative feedback inhibition can lead to continuous anovulation in PCOS subjects (Zhang et al. 2012). Thus, CGRP which is an osteoanabolic peptide is found to be elevated in PCOS. Valentijn and coworkers (Valentijn et al. 1997), in a study on ovariectomized rat, reported that CGRP stimulates the production of the growth factor IGF-1 and inhibits that of the TNF $\alpha$ by osteoblast, suggesting that CGRP may control bone cell activity. Thus, this elevation in CGRP to some extent may help in maintaining bone mass in 
PCOS patients despite the effect of decreased vitamin D and increased PTH which will decrease BMD.

\section{Summary and conclusion}

PCOS is a complex disorder and several components of the syndrome may be related to bone density. Various lines of evidence regarding the hormonal imbalance in PCOS tend to support the association of PCOS and osteoporosis. The hormones including GnRH, LH/FSH ratio, estrogens, androgens, insulin, cortisol, GH, vitamin D and PTH are found to be altered in PCOS patients. Hyperinsulinemia associated with insulin resistance plays a vital role in the development of PCOS. Hyperinsulinemia can increase androgen level, which in turn can increase insulin resistance. Insulin signaling is found to increase bone resorption by decreasing osteoprotegerin and increasing RANKL expression. Therefore, it is possible that high level of insulin in women suffering from PCOS may bind to insulin receptor in osteoblast and reduce the bone formation and increase bone resorption.

The decrease in the aromatase activity, increased $\mathrm{LH} / \mathrm{FSH}$ ratio, rapid $\mathrm{LH} / \mathrm{GnRH}$ pulse, increased activity of $\mathrm{C}_{17,20}$-lyase, $17 \alpha$-hydroxylase, $5 \alpha$-reductase and $3 \beta$-HSD levels are some of the reasons for the increased androgen and decreased estrogen level seen in PCOS. Both adrenal and gonadal androgens contribute to hyperandrogenemia in PCOS. Other than through sex steroid receptors, androgens influence bone metabolism through various other pathways involving IL-6, prostaglandin $\mathrm{E}_{2}$, PTH, vitamin $\mathrm{D}_{3}$, TGF $\beta$ and IGF-1, IGF-2 and so forth. Hyperandrogenemia helps to preserve bone mass in PCOS women. However, androgens have a positive effect on bone only in the presence of estrogen. Adrenal androgen excess in PCOS is associated with increased inactivation of cortisol which in turn leads to elevated level of TNFo and IL-1 $\beta$ that could probably result in chronic inflammatory bone disease and bone loss. However, more research is still needed to unravel the exact mechanism by which androgen affects the BMD of PCOS subjects. Care should be taken while treating the subjects with anti-androgenic drug. The exact mechanism by which an anti-androgenic drug is affecting the BMD is also not fully identified. Identifying the exact mechanism leads to formulate an effective strategy to treat bone-related disorders in PCOS women.

Growth hormone, an important hormone for bone remodeling, is found to be decreased in PCOS patients. Decreased GH and decreased GH/IGF ratio seen in PCOS subjects will cause a reduction in bone remodeling and thus decrease BMD. The calciotrophic hormones, PTH and vitamin D are altered in PCOS. Insulin resistance is associated with decreased concentrations of vitamin D metabolites and increased PTH concentrations, which can increase bone resorption. PTH can independently cause hyperandrogenemia in PCOS women. CGRP, a member of calcitonin family, which inhibits bone resorption, is found to be positively correlated with the hormonal and metabolic parameters like insulin resistance, LH/FSH ratio and testosterone level which are all the salient features of PCOS. However, this elevation in CGRP to some extent may help in maintaining bone mass in PCOS but require detailed study.

Thus, PCOS, as a syndrome, has got multiple components including reproductive, metabolic and hormonal, with long-term health concerns that cross the life span. Although the mechanisms are not well understood, the hormonal imbalance in PCOS women is affecting the BMD resulting in osteoporosis. The adverse effect of the hormonal imbalance reported in PCOS patients on bone metabolism is clearly evident on the article reviewed. Also the treatment of this disorder should be focused on reduction of androgen-associated syndrome with decreased fracture risk. Fig. 9 shows a schematic representation of hormonal alterations in PCOS subjects and their influence on bone metabolism.

\section{Future prospectives}

The relationship between $\mathrm{BMD}$ and the hormonal imbalance in patients with PCOS (Table 1) offers important insights into the potential synergies between estrogens and androgens in protecting against osteoporosis. The diversity of the syndrome influences bone mass through interrelated metabolic events not necessarily mediated by androgens alone. This review also indicates that the study of the regulation of bone metabolism in PCOS patients may offer a novel endocrine perspective on treating osteoporosis in PCOS patients, and has identified the following lacunae:

1. Mechanism behind the increased bone resorption despite reduction in TRAP $5 \mathrm{~b}$ upon elevated insulin level.

2. Androgen is the important hormone for maintaining BMD in males. But in females, this elevated androgen level is not necessarily helping in the development of BMD and has some adverse effects too. So what is

Published by Bioscientifica Ltd 
the relevance of this elevated androgen level in BMD of PCOS women? Whether the expression of $5 \alpha-$ reductase and aromatase are differently regulated in the osteoblast of PCOS subjects? Also there is evidence of cortisol inactivation during PCOS, which could lead to increase in inflammatory cytokines TNF $\alpha$ and IL-1 $\beta$ and could result in the deterioration of bone mineral density. This can be studied using a co-culture system involving thecal, osteoblastic and osteoclastic cells.

3. Relevance of decreased anti-inflammatory hormone, cortisol, with a corresponding increase in inflammatory cytokines TNF $\alpha$ and IL-1 $\beta$ in the BMD of PCOS women.

4. Study of alteration in growth hormone, IGF and IGFBP and its subsequent effect on osteoclastic alteration in PCOS subjects. Decreased level of GH seen in PCOS condition can affect the level of IGF also. These are involved in both bone formation as well as resorption. What is the effect of this variation in the BMD of PCOS requires further study. A detailed study regarding which of the six IGFBPs is getting altered in PCOS subjects will help to understand whether there occurs a catabolic or anabolic change in bone during PCOS in relation to GH, IGF and IGFBP levels.

\section{Declaration of interest}

The authors declare that there is no conflict of interest that could be perceived as prejudicing the impartiality of this review.

\section{Funding}

This research did not receive any specific grant from any funding agency in the public, commercial or not-for-profit sector.

\section{Acknowledgements}

The authors wish to thank the Managing Director, Chief Executive officer, Vice Chancellor, Registrar of Karpagam University for the constant support and encouragement.

\section{References}

Abu EO, Horner A, Kusec V, Triffitt JT \& Compston JE 1997 The localization of androgen receptors in bone. Journal of Clinical Endocrinology and Metabolism 82 3493-3497. (doi:10.1210/ jcem.82.10.4319)

Adashi EY, Resnick CE, D’Ercole J, Svoboda ME \& Van Wyk JJ 1985 Insulin-like growth factors as intraovarian regulators of granulosa cell growth and function. Endocrine Reviews 6 400-404. (doi:10.1210/ edrv-6-3-400)
Alvarez JA \& Ashraf A 2010 Role of vitamin in insulin secretion and insulin sensitivity for glucose homeostasis. International Journal of Endocrinology 2010 351-385. (doi:10.1155/2010/351385)

Baillargeon JP 2005 Use of insulin sensitizer in PCOS. Current Opinion in Investigational Drugs 6 1012-1022.

Balen AH, Conway GS, Kaltsas G, Techatrasak K, Manning PJ \& West C 1995 Polycystic ovary syndrome: the spectrum of the disorder in 1741 patients. Human Reproduction Update 10 2107-2111.

Baptiste CG, Battista MC, Trottier A \& Baillargeon JP 2010 Insulin and hyperandrogenism in women with PCOD. Journal of Steroid Biochemistry and Molecular Biology 122 1-22. (doi:10.1016/j. jsbmb.2009.12.010)

Barnes RB, Rosenfield RL, Burstein S \& Ehrmann DA 1989 Pituitaryovarian responses to nafarelin testing in the polycystic ovary syndrome. New England Journal of Medicine 320 559-565. (doi:10.1056/NEJM198903023200904)

Bilezikian JP, Morishima A \& Bell J 1998 Increased bone mass as a result of estrogen therapy in a man with aromatase deficiency. New England Journal of Medicine 339 599-603. (doi:10.1056/ NEJM199808273390905)

Blank S, Maccarte CR \& Marshall JC 2006. The origins and sequelae of abnormal neuroendocrine function in polycystic ovary syndrome. Human Reproduction Update 12 351-361. (doi:10.1093/humupd/ dml017)

Boyce BF, Li P, Yao Z, Zhang Q, Badell IR, Schwarz EM, O'Keefe RJ \& Xing L 2005 TNF-alpha and pathologic bone resorption. Keio Journal of Medicine 54 127-131. (doi:10.2302/kjm.54.127)

Carter PH \& Schipani E 2006 The roles of parathyroid hormone and calcitonin in bone remodeling: prospects for novel therapeutics. Endocrine Metabolic and Immune Disorder-Drug Targets 6 59-76. (doi:10. 2174/187153006776056666)

Cedars MI, Steingold KA, de Ziegler D, Lapolt PS, Chang RJ \& Judd HL 1992 Long-term administration of gonadotropin-releasing hormone agonist and dexamethasone: assessment of the adrenal role in ovarian dysfunction. Fertility and Sterility 57 495-500. (doi:10.1016/S00150282(16)54890-0)

Chada 1, Průsa R, Bronský J, Pechová M, Kotaska K \& Lisá L 2003 Inhibin $\mathrm{B}$, follicle stimulating hormone, luteinizing hormone, and estradiol and their relationship to the regulation of follicle development in girls during childhood and puberty. Physiological Research 52 341-346.

Clemens TL \& Karsenty G 2011 The osteoblast an insulin target cell controlling glucose homeostasis. Journal of Bone and Mineral Research 26 677-680. (doi:10.1002/jbmr.321)

Coutinho AE \& Chapman KE 2011 The anti-inflammatory and immunosuppressive effects of glucocorticoids, recent developments and mechanistic insights. Molecular and Cellular Endocrinology 335 2-13. (doi:10.1016/j.mce.2010.04.005)

Dasgupta S, Dutta J, Annameneni S, Kudugunti N \& Mohan Reddy B 2015 Association of vitamin D receptor gene polymorphisms with polycystic ovary syndrome among Indian women. Indian Journal of Medical Research 142 276-285. (doi:10.4103/0971-5916.166587)

Dumitrescu R, Mehendintu C, Briceag I, Purcarea VL \& Hudita D 2015 The polycystic ovarian syndrome: An update on mechanical and hormonal mechanism. Journal of Medicine and Life 8 142-145.

Dunaif A 1997 Insulin resistance and the polycystic ovary syndrome: mechanism and implications for pathogenesis. Journal of Endocrine Reviews 18 774-800. (doi:10.1210/er.18.6.774)

Ehrmann DA 2005 Polycystic ovary syndrome. New England Journal of Medicine 352 1223-1236. (doi:10.1056/NEJMra041536)

Gambineri A, Forlani G, Munarini A, Tomassoni F, Cognigni GE, Ciampaglia W, Pagotto U, Walker BR \& Pasquali R 2009 Increased clearance of cortisol by 5beta-reductase in a subgroup of women with adrenal hyperandrogenism in polycystic ovary syndrome. Journal of Endocrinological Investigation 32 210-218. (doi:10.1007/BF03346454) http://joe.endocrinology-journals.org

DOI: 10.1530/JOE-16-0405
() 2017 Society for Endocrinology Printed in Great Britain
Published by Bioscientifica Ltd 
Goren HG, Brandes JM \& Bar-Ami S 1990 Altered steroidogenic pattern of human granulosa-lutein cells in relation to cumulus cell culture morphology. Journal of Steroid Biochemistry 36 457-464. (doi:10.1016/0022-4731(90)90088-A)

Hall JE, Taylor AE, Hayes FJ \& Crowley WK 1998 Insights into hypothalamicpituitary dysfunction in polycystic ovary syndrome. Journal of Endocrinological Investigation 21 602-611. (doi:10.1007/BF03350785)

Hofbauer LC \& Khosla S 1999 Androgen effect on bone metabolism: recent progress and controversies. European Journal Endocrinology 140 271-286. (doi:10.1530/eje.0.1400271)

Holte J 1996 Disturbances in insulin secretion and sensitivity in women with the polycystic ovary syndrome. Baillieres Clinical Endocrinology and Metabolism 10 221-247. (doi:10.1016/S0950-351X(96)80085-1)

Huang S, Kaw M, Harris MT, Ebraheim N, McInerney MF, Najjar SM \& Lecka-Czernik B 2010 Decreased osteoclastogenesis and high bone mass in mice with impaired insulin clearance due to liver-specific inactivation to CEACAM1. Bone 46 1138-1145. (doi:10.1016/j. bone.2009.12.020)

Jakimiuk AJ, Weitsman SR \& Magoffin DA 1999 5a-Reductase activity in women with polycystic ovary syndrome. Journal of Clinical Endocrinology and Metabolism 84 2414-2418. (doi:10.1210/ jc.84.7.2414)

Jehle MP, Schulten K, Schulz W, Jehle DR, Stracke S, Manfras B, Boehm BO, Baylink DJ \& Mohan S 2010 Serum levels of insulin like growth factor (IGF)I and IGF binding protein (IGFBP) 1 to 6 and their relationship to bone metabolism in osteoporosis patients. European Journal of International Medicine 14 32-38. (doi:10.1016/S09536205(02)00183-8)

Joshi B, Mukherjee S, Patil A, Purandare A, Chauhan S \& Vaidaya R 2014 A cross-sectional study of polycystic ovarian syndrome among adolescent and young girls in Mumbai, India. Indian Journal of Endocrinology and Metabolism 18 317-324. (doi:10.4103/22308210.131162)

Kasperk C, Wergedal J \& Farley J 1989 Androgen directly stimulate proliferation of bone cells in vitro. Endocrinology 124 1576-1579. (doi:10.1210/endo-124-3-1576)

Katz E, Ricciarelli E \& Adashi EY 1993 The potential relevance of growth hormone to female reproductive physiology and pathophysiology. Fertility and Sterility 59 8-34. (doi:10.1016/S0015-0282(16)55610-6)

Klein GL 2014 Insulin and bone: recent developments. World Journal of Diabetes 5 14-16. (doi:10.4239/wjd.v5.i1.14)

Kumar S, Olukoga AO, Gordon C, Mawer EB, France M \& Hosker JP 1994 Impaired glucose tolerance and insulin insensitivity in primary hyperparathyroidism. Clinical Endocrinology 40 47-53. (doi:10.1111/j.1365-2265.1994.tb02442.x)

Lin IC, Slemp AE, Hwang C, Sena-Esteves M, Nah HD \& Kirschner RE 2007 Dihydrotestosterone stimulates proliferation and differentiation of fetal calvarial osteoblasts and dural cells and induces cranial suture fusion. Plastic and Reconstructive Surgery 120 1137-1147. (doi:10.1097/01.prs.0000279527.99734.bf)

Liu YX \& Hsueh AJ 1986 Synergism between granulosa and thecainterstitial cells in estrogen biosynthesis by gonadotropin-treated rat ovaries: studies on the two-cell, two-gonadotropin hypothesis using steroid antisera. Biology of Reproduction 35 27-36. (doi:10.1095/ biolreprod35.1.27)

Mathis SL, Farley RS, Fuller DK, Jetton AE \& Caputo JL 2013 The relationship between cortisol and bone mineral density in competitive male cyclists. Journal of Sports Medicine 2013 1-7. (doi:10.1155/2013/896821)

McCarty MF 1995 Anabolic effects of insulin on bone suggest a role for chromium picolinate in preservation of bone density. Medical Hypothesis 45 241-246. (doi:10.1016/0306-9877(95)90112-4)

Mendelson CR \& Kamat A 2007 Mechanisms in the regulation of aromatase in developing ovary and placenta. Journal of Steroid Biochemistry and Molecular Biology 106 62-70. (doi:10.1016/j. jsbmb.2007.05.001)
Miller WL 2002 Androgen biosynthesis from cholesterol to DHEA. Molecular and Cellular Endocrinology 198 7-14. (doi:10.1016/S03037207(02)00363-5)

Moghetti P, Castello R, Zamberlan N, Rossin M, Gatti D, Negri C, Tosi F, Muggeo M \& Adami S 1999 Spironolactone, but not flutamide, administration prevents bone loss in hyperandrogenic women treated with gonadotropin-releasing hormone agonist. Journal of Clinical Endocrinology and Metabolism 84 1250-1254. (doi:10.1210/ jc.84.4.1250)

Morales AJ, Laughlin GA, Butzow T, Maheshwari H, Baumann G \& Yen SS 1996 Insulin, somatotropic, and luteinizing hormone axes in lean and obese women with polycystic ovary syndrome: common and distinct features. Journal of Clinical Endocrinology and Metabolism $\mathbf{8 1}$ 2854-2864. (doi:10.1210/jcem.81.8.8768842)

Muller EE, Locatelli V \& Cocchi D 1999 Neuroendocrine control of growth hormone secretion. Physiological Reviews 79 511-607.

Muscogiuri G, Mitri J, Mathieu C, Badenhoop K, Tamer G, Orio F, MezzaT, Vieth R, Colao A \& Pittas A 2014 Vitamin D as a potential contributor in endocrine health and disease. European Journal of Endocrinology 171 R101-R110. (doi:10.1530/EJE-14-0158)

Nelson VL, Legro RS, Strauss JF \& Mcallister JM 1999 Augmented androgen production is a stable steroidogenic phenotype of propagated theca cells from polycystic ovaries. Molecular Endocrinology 13 946-957. (doi:10.1210/mend.13.6.0311)

Nestler JE, Jakubowicz DJ, Vargas FA, Brik C, Quintero N \& Medina F 1998 Insulin stimulates testosterone biosynthesis by human thecal cells from women with PCOS by activating its own receptor and using inositol glycan mediators as the signal transduction system. Journal of Clinical Endocrinology and Metabolism 83 2001-2005. (doi:10.1210/ jcem.83.6.4886)

Notelovitz M 2002 Androgen effects on bone and muscle. Fertility and Sterility 77 S34-S41. (doi:10.1016/S0015-0282(02)02968-0)

Olney RC 2003 Regulation of bone mass by growth hormone. Medical and Pediatric Oncology 41 228-234. (doi:10.1002/mpo.10342)

Panidis D, Balaris C, Farmakiotis D, Rousso D, Kourtis A, Balaris V, Katsikis I, Zournatzi V \& Kandarakis ED 2005 Serum parathyroid hormone concentrations are increased in women with polycystic ovary syndrome. Clinical Chemistry 51 1691-1697. (doi:10.1373/ clinchem.2005.052761)

Paradisi R, Grossi G, Venturoli S, Capelli M, Pocu E \& Fabbri R 1988 Evidence for an hypothalamic alteration of catecholamine metabolism in polycystic ovary syndrome. Clinical Endocrinology 29 317-326. (doi:10.1111/j.1365-2265.1988.tb01230.x)

Rodin A, Thakkar H, Taylor N \& Clayton R 1994 Hyperandrogenism in polycystic ovary syndrome. Evidence of dysregulation of 11 betahydroxysteroid dehydrogenase. New England Journal of Medicine 330 460-465. (doi:10.1056/NEJM199402173300703)

Sawalha AH \& Kovats S 2008 Dehydroepiandrosterone in systemic lupus erythematosus. Current Rheumatology Reports 4 286-291. (doi:10.1007/ s11926-008-0046-1)

Sawetawan C, Carr BR, McGee E, Bird IM, Hong TL \& Rainey WE 1996 Inhibin and activin differentially regulate androgen production and 17 alpha-hydroxylase expression in human ovarian thecal-like tumor cells. Endocrinology 148 13-21. (doi:10.1677/ joe.0.1480213)

Shao W \& Espenshade PJ 2012 Expanding roles for SREBP in metabolism. Cell Metabolism 16 414-419. (doi:10.1016/j.cmet.2012.09.002)

Shimodaira K, Fujikawa H, Okura F, Shimzo Y, Saito H \& Yanaibara T 1996 Osteoblast cells (MG 63 and HOS) have aromatase and $5 \alpha$-reductase activities. Biochemistry and Molecular Biology International 39 109-116. (doi:10.1080/15216549600201111)

Sterling E 2015 Hormone levels and PCOS. In Contemporary OB/GYN 7 November 2015 news story. ModernMedicine Network. Iselin, NJ, USA: UBM Medica. (available at: http://contemporaryobgyn. modernmedicine.com/contemporary-obgyn/news/hormone-levelsand-pcos) 
Stewart PM, Shackleton CH, Beastall GH \& Edwards CR 1990 $5 \alpha$-Reductase activity in polycystic ovary syndrome. Lancet 335 431-433. (doi:10.1016/0140-6736(90)90664-Q)

Thomas DM, Udagawa N, Hards DK, Quinn JM, Moseley JM, Findlay DM \& Best JD 1998 Insulin receptor expression in primary and cultured osteoclast-like cells. Bone 23 181-186. (doi:10.1016/S87563282(98)00095-7)

Thomson RL, Spedding S \& Buckley JD 2012 Vitamin D in the aetiology and management of polycystic ovary syndrome. Clinical Endocrinology 77 343-350. (doi:10.1111/j.1365-2265.2012.04434.x)

Thorén M, Hilding A, Brismar T, Magnusson P, Degerblad M, Larsson L, Sääf M, Baylink DJ \& Mohan 1998 Serum levels of insulin-like growth factor binding proteins (IGFBP) -4 and -5 correlate with bone mineral density in growth hormone (GH)-deficient adults and increase with GH replacement therapy. Journal of Bone and Mineral Research 13 891-899. (doi:10.1359/jbmr.1998.13.5.891)

Tsilchorozidou T, Honour JW \& Conway GS 2003 Altered cortisol metabolism in polycystic ovary syndrome: insulin enhances 5-reduction but not the elevated adrenal steroid production rates Journal of Clinical Endocrinology and Metabolism 88 5907-5913. (doi:10.1210/jc.2003-030240)

Tsilchorozidou T, Overto C \& Conway GS 2004 The pathophysiology of polycystic ovarian syndrome. Clinical Endocrinology 60 1-17. (doi:10.1046/j.1365-2265.2003.01842.x)

Valentijn K, Gutow AP, Troiano N, Gundberg C, Gilligan JP \& Vignery A 1997 Effects of calcitonin gene-related peptide on bone turnover in ovariectomized rats. Bone 21 269-274. (doi:10.1016/S87563282(97)00142-7)

Wang H-S \& Wang T-H 2003 Polycystic ovary syndrome (PCOS), insulin resistance and insulin-like growth factors (IGFs)/IGF-binding proteins (IGFBPs). Chang Gung Medical Journal 26 540-553. (available at: http://memo.cgu.edu.tw/cgmj/2608/260801.pdf)

Wang \& Zhong 2013 Insulin effect on RANKL and OPG expression in human osteoblast-like MG63 cells. Turkish Journal of Medical Science 43 631-636. (doi:10.3906/sag-1203-108)

Wareham NJ, Byrne CD, Carr C, Day NE, Boucher BJ \& Hales CN 1997 Glucose intolerance is associated with altered calcium homeostasis: a possible link between increased serum calcium concentration and cardiovascular disease mortality. Metabolism 46 1171-1177. (doi:10.1016/S0026-0495(97)90212-2)

Wu X, Sallinen K, Zhou SY, Su YH, Pöllänen P \& Erkkola R 2000 Androgen excess contributes to altered growth hormone/insulinlike growth factor-1 axis in nonobese women with polycystic ovary syndrome. Fertility and Sterility 73 730-734. (doi:10.1016/S00150282(99)00634-2)

Zborowski JV, Evelyn O, Talbott \& Jane AC 2000 Polycystic ovary syndrome, androgen excess and impact on the bone. Obstetrics and Gynecology Clinics 8 135-151. (doi:10.1016/s0889-8545(05)70190-x)

Zhang Z, Gong F \& Lu XG 2012 Plasma level of calcitonin gene-related peptide in patients with polycystic ovary syndrome and its relationship to hormonal and metabolic parameters. Peptides 34 343-348. (doi:10.1016/j.peptides.2012.01.018)

Received in final form 24 October 2016

Accepted 28 November 2016

Accepted Preprint published online 28 November 2016
๑) 2017 Society for Endocrinology Printed in Great Britain
Published by Bioscientifica Ltd. 